\title{
Decentralizing HIV/AIDS Education in the Philippines: A Measure of Awareness from the Grassroots
}

\author{
Elvira H. Ronquillo', Anthony B. San Pedro1, Lorna B. Bote², John Eric Dizon ${ }^{3}$ \\ ${ }^{1}$ Provincial Cooperative and Entrepreneurship Development Office, Palayan City, Philippines \\ ${ }^{2}$ Provincial Planning and Development Office, Provincial Government of Nueva Ecija, Palayan City, Philippines \\ ${ }^{3}$ Rural Health Office, San Jose City, Philippines \\ Email: anthonybasasanpedro@yahoo.com
}

How to cite this paper: Ronquillo, E.H., Pedro, A.B.S., Bote, L.B. and Dizon, J.E. (2017) Decentralizing HIV/AIDS Education in the Philippines: A Measure of Awareness from the Grassroots. Open Access Library Journal, 4: e4167.

https://doi.org/10.4236/oalib.1104167

Received: November 17, 2017

Accepted: December 12, 2017

Published: December 15, 2017

Copyright $\odot 2017$ by authors and Open Access Library Inc.

This work is licensed under the Creative Commons Attribution International License (CC BY 4.0).

http://creativecommons.org/licenses/by/4.0/

\begin{abstract}
The HIV/AIDS is pandemic. The study measured the level of understanding of the community on HIV/AIDS as part of measuring the impact of decentralized initiative against HIV/AIDS. It applies the Systems' Theory of Policy Process developed by David Easton. The study showed that: age, gender, civil status and religion have nothing to do with the level of understanding of the HIV/AIDS. The study revealed that respondents' of the issue of HIV/AIDS as measured in terms of knowledge, attitudes and beliefs fall within the median range of scores: 2.89 for knowledge, 2.59 for beliefs and 2.93 for attitudes. The study further concluded that there is no significant relationship between the personal profile of the respondents and their level of understanding. The study found that heightened understanding of HIV/AIDS among Rural Health Unit 4 respondents was due to decentralized mass information and dissemination campaign of the Local Government Unit.
\end{abstract}

\section{Subject Areas}

Education, Politics, Sociology

\section{Keywords}

Decentralization, HIV/AIDS Awareness, Philippines

\section{Introduction}

Among the many developments that took place in the Philippines for the past decades, it was the advent of decentralization resulting to greater responsibility 
on the sub-national government to implement programs and projects within its political boundaries [1]. Along with the concept of decentralization is a performance measurement that depends to a great extent on the impact of governmental programs to the community [2] LGU Performance measured in terms of quantifiable outputs of one system consisting of sub-systems or organization [3]. The concept of decentralization is coupled with the concept of devolution of governmental functions from central government to local government units [4]. It is the relationship of the national government and local government imposing upon the burden to the LGU to undertake initiative and participate in finding solutions to many local problems. Decentralization also infused upon the LGU greater transparency and accountability in the discharge of local affairs [5]. It is noteworthy to mention that despite devolution of health function, the national government budget remains concentrated in the national programs and projects and the regional health programs as its primary concern [6]. This leaves the local health unit to depend to its own resources to implement local health programs financed by the Internal Revenue Allotment (IRA) that it automatically receives from the national government [7]. Community participation as the primary measure of the success of LGU program is seldom evaluated because of the limited budget LGU could use to finance commissioned program evaluation. This study is therefore intended to assess the impact of information drives on HIV/ AIDS in Regional Health Unit 4 (RHU4) residents in the City of San Jose in the Philippines.

The City of San Jose is a component city situated in the Northern part of the province of Nueva Ecija, Philippines. It is one of the five component cities of the province. It has a Rural Health Unit Department primarily in charge of the following functions: To deliver the complete range of health care as well as administrative support services to the community including a) Child immunization; b) Primary health care; c) Prevention, detection and treatment of communicable disease (STD/HIV/AIDS/TB/Rabies);

As part of its primary function, the RHU sponsored series of seminars and information drive on communicable diseases. In the last three years, the focus of the campaign was on the HIV/AIDS. The campaign became the corner stone of the Health Unit's Information Dissemination Drive. The primary objective of the program is to contain the spread of HIV/AIDS among the most at risk population and general population through education campaign. The programs attached to the objective are the following:

1) fight against stigma and discrimination;

2) establishment of free HIV counseling;

3) maximum possible condom Use Program;

4) peer education outreach;

5) multi-sectoral coordination through Philippine National AIDS Council (PNAC);

6) educate and empower the communities; 
7) community seminar and workshop to avoid stigmatization;

8) establishment of social hygiene clinics.

In many studies, the elderly are mostly affected by HIV/AIDS. According to [8], adults are found to be infected by AIDS. It was found that there was a $10 \%$ increase in the number of older people infected by the virus. There are reasons cited why they are prone to infections: reluctance to use protection during sexual intercourse; the propensity to have sex with relatively younger people; older adults engaged in activities risky for HIV infections. In a study conducted by Makinawe et al., it was found that the productive labor sector in society suffers from HIV virus diminishing to a certain extent the number of employable youth and spiraling increase in the cost of medication, travel and living (Union, n.d.). HIV also affects psychological state of victims. The results of the study by [9] and [10] and [11] showed that persons infected by HIV, experiences hopelessness, loneliness, shame and fear, humiliation and stigmatization.

Most studies are undertaken in learning institutions measuring the level of awareness on practices, beliefs, and attitudes of respondents. Many of the respondents are nursing students, primary school teachers, and trade and tourism employees. Only a few dwell on the study of community members. Many of the study also measured awareness and their implications to curriculum. The present study used respondents -members of the community and measures their level of awareness on HIV/AIDs after series of seminars and information dissemination were undertaken by RHU4. The focus of the study was to measure the community members attitudes, beliefs and knowledge on the HIV AIDS. The present study deals more on policy implementation with regard to AIDS program implementation.

\section{Statement of the Problem}

The study aimed at measuring the effects of the programs/activities of the Rural Health Unit 4 of San Jose City, Nueva Ecija and provide recommendations for further improvement, the study entitled "Decentralizing HIV/AIDS Education in the Philippines: A Measure of Understanding of the Grassroots" The general objective is subdivided to the following specific questions, to wit;

1) How may the profile of the respondents be described in terms of:

1.1) Age

1.2) Gender

1.3) Civil status

1.4) Religion

2) How may the impact of Rural Health Education on HIV/AIDS of the Local Government Unit of San Jose on Rural Health 4 residents be described in terms of:

2.1) Knowledge on the nature and causes

2.2) Beliefs on the communicable disease;

2.3) Attitudes towards HIV AIDS. 
3) How may the level of awareness of the respondents relate to their personal profile;

4) Given the findings of the study, what policy recommendations for information drive may be submitted?

The study is guided by the following temporary answers to the questions:

Hypothesis 1:

The study hypothesized that the information drive undertaken by the City government for RHU4 made them better understand the communicable disease in terms of knowledge, beliefs and attitudes towards HIV/AIDS.

Hypothesis 2:

There is no correlation between the residents' personal profile and level of awareness on AIDS.

The hypotheses are tested using Pearson Product Moment Correlation taking into consideration the nominal variable. The tool shall prove whether their personal profile has something to do with their understanding of AIDS.

\section{Methodology}

\subsection{Research Design}

The research method employed in the study is qualitative descriptive. This method of research is suited to the study as the latter intended not only to describe into the existing [12] understanding of the RHU4 residents on HIV/AIDS but also to inquire into the reasons why they have such degree of understanding [13]. It is appropriate to the study considering its aim of describing the event, phenomenon and understanding of AIDS. Accordingly, Kash \& Darling mentioned that qualitative descriptive research method is appropriate to the concept of the study not only because it relates to the qualitative interpretation of perceived variable/s as independent variables to dependent variable (level of awareness consisting of the attitudes, beliefs and knowledge on AIDS) as independent variables. The Descriptive method of research "describes and interprets what is. It is concerned with the conditions or relationships that exists; practices that prevail ,beliefs ,points of view, or attitude that are held, processes that are going on ,effects that are being felt or trends that are developing." The descriptiveness of the nature of this proposed study is reinforced by a qualitative interpretation of the data gathered. According to [14] in her book "Conducting Research A Practical Application", Qualitative research answers not only what is but also why and how a certain event is taking place. The research method is presented in Figure 1.

\subsection{Theoretical Framework}

A theory is a combination of different variables woven together in an effort to explain a certain phenomenon or event, concept or activity. It is sometimes considered as a product of practice or a practice in theory [15]. The study adheres to the Systems Theory of Policy Process developed from David Easton's systems 


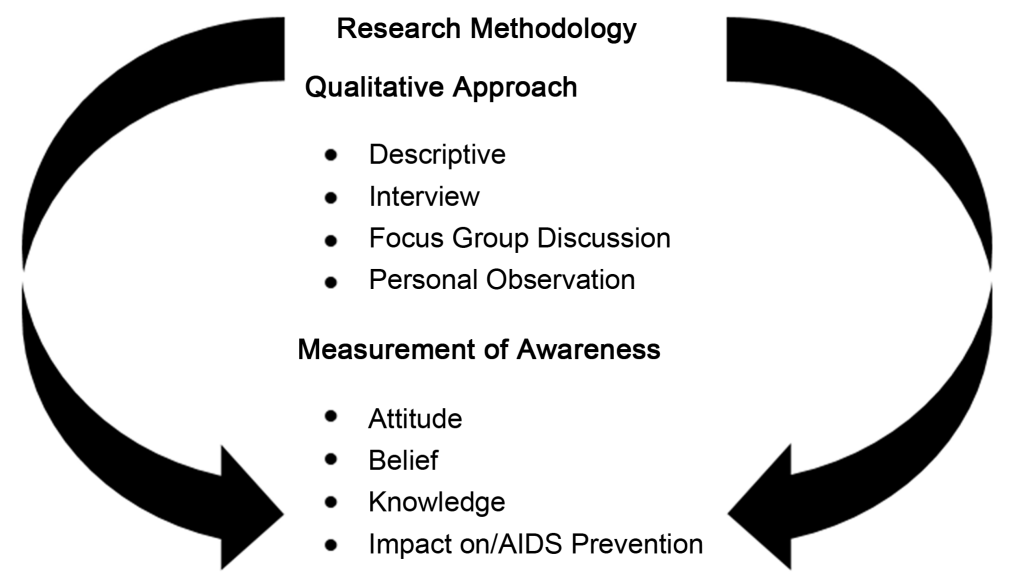

Figure 1. Research methodology.

approach to the analysis of political system. The theory posits that public policy is not simply a government output but must be considered as a cycle where a policy has to undergo cycles of evaluation. Each of the cycles is differentiated from a related cycle of policy. The issue of HIV/AIDS is brought about by a policy demand. The pressing problem of widespread contamination and increasing number of Filipinos infected by the deadly virus forced the DOH to face the problem squarely by giving priority to awareness campaigns in all possible venues and geographical locations [8]. The need to implement policy on HIV AIDS educational campaign is a policy decision arising from a policy demand. As part of the political system, the Local Government Units play a very vital role to implement the policy. The policy outputs of the local government units are seen in its intensified campaigns for HIV AIDS Awareness. This policy output is made possible by appropriating financial support to the output. The policy output in the form of flyers, seminar-workshop, and education campaign through social media create impacts. The impacts are the result of the education campaign part of the RHU4 office function. Impacts are the consequences intended or unintended resulting from political action or inaction. The process of Inputs-Process-Outputs is the theoretical model of David Easton from which a policy impact may be measured. Therefore, as the study dealt with the issue of HIV AIDS as part of the DOH office policy cascaded to the LGU which can be analyzed using the System's theoretical model. Thus the study looked at the awareness campaign as part of the system's function that creates outputs and ultimate impacts to the community in terms of better understanding and appreciation of the issue of HIV AIDS. As part of the system's operations, the study would also identify possible intended results which later on would form part of the new inputs from which another policy decision may be based. The policy input, in the form of study results may again be subjected to the LGU operation to better improve the actual policy implementation on the ground. The study as an output at the same time a new feedback may serve as basis of a renewed LGU RHU4 information drive against the spread of HIV AIDS. The entire theoretical 
framework (process) is shown by the diagram below (Figure 2), to wit.

\subsection{Conceptual Framework}

Learning is one of the most important activities in which human engaged. It is at the very core of the educational process. The study follows the same line of reasoning when it relates to the concept of AIDS. The learning continuum presents the importance of the study in so far as AIDS prevention and control is concerned. The continuum begins with the awareness program sponsored by the LGU Health Unit process provided by the unit as the agent of knowledge. Through information drive, activities and programs of the Health Unit, it influenced beliefs, attitudes and knowledge of the community on the issue. The AIDS awareness campaign shows the continuous cycle of influencing the community on health education including related concepts important to understanding the disease. Such implication leads to further understanding and prevention. Such preventive/defensive conception of the paradigm is rooted from the fact that until this date no known cure for the disease has been invented by medical science.

\subsection{Sample and Sampling Procedure}

The sample consists of 120 residents of RHU4 of the local government of San Jose. The original number of respondents was 460 individuals. However, for the purpose of convenience, as many did not possess the above cited criteria for determining sample size the researcher opted to include only 120 of the residents. The researcher identified the respondents whose criteria are suited to the study purpose. A purposive sampling procedure was observed with the following characteristics as the bases for identification: 1) Age of majority; 2) resident of the city within the RHU4 3) must have attended and actively participated in the HIV/AIDS program of the LGU.

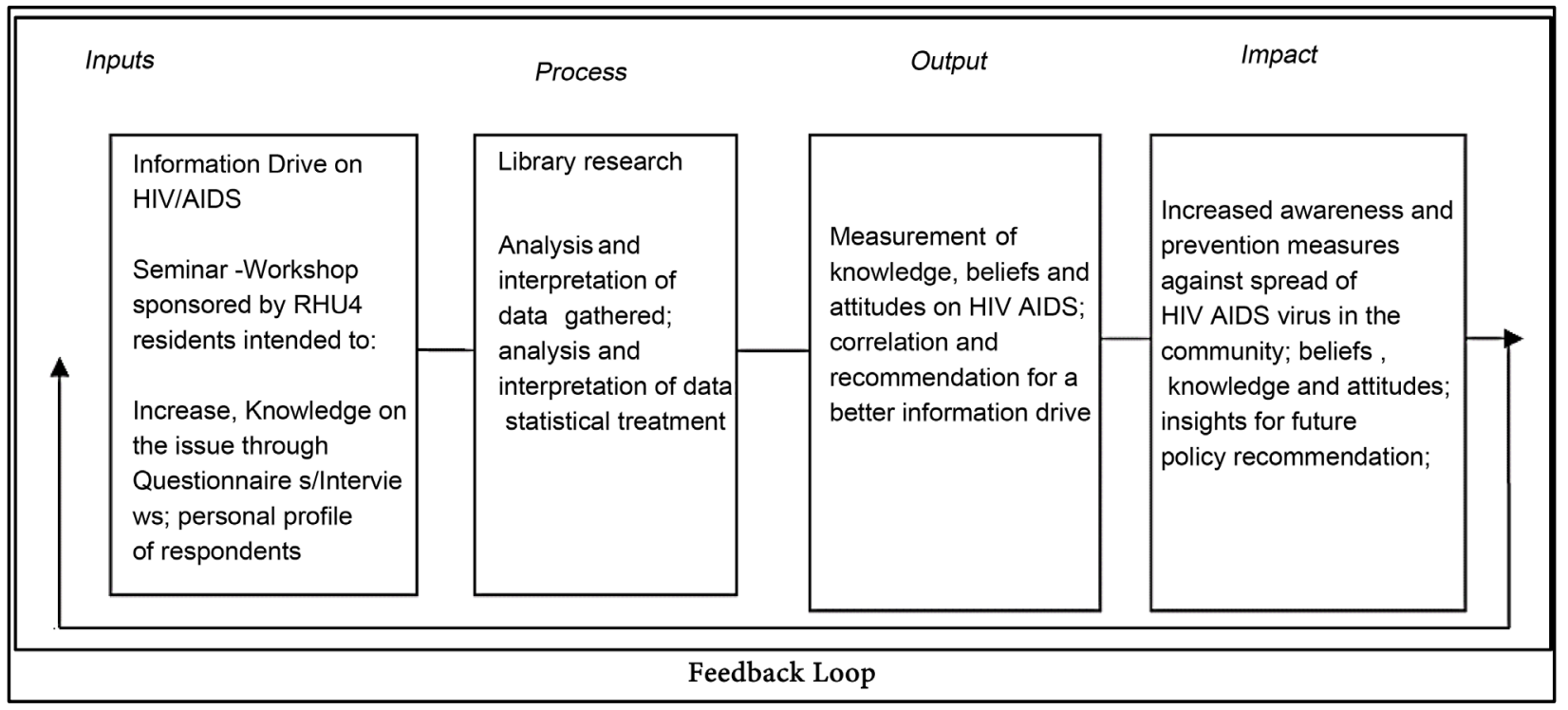

Figure 2. The system's theory of policy process. 


\subsection{Data Gathering Procedure}

The primary data were gathered through the use of survey questionnaires. The survey questionnaire is divided into three domains. The domain for knowledge, beliefs and attitudes towards HIV/AIDS. Interviews with respondents were also undertaken to reinforce the answers given in the survey questionnaires. The questionnaires are translated to native tongue. The questionnaires consisted of 30 items subdivided into three domains. After the instrument was subjected to internal and external validity test, it was distributed in the community on the 7th of February, 2017. Majority of the filled out instruments were collected within 2 days but some were collated after 3 - 5 days. The collected data were subjected to statistical treatment using SPS Software.

\subsection{Statistical Treatment}

The statistical treatment used in the study is simple measure of central tendency on the part where such treatment was applicable. The part 2 of the questionnaires was subjected to simple statistical treatment. The first part was treated with $t$ test to establish relationship between demographic variables and awareness on knowledge, beliefs, and attitudes.

\section{Results and Discussion}

\subsection{Profile of the Respondents}

The Table 1 shows the profile of the respondents:

The participants to the study are 120 residents of San Jose City. They are all living within the administrative jurisdiction of RHU4. As the table presented, the age ranges and the number of respondents are almost equally distributed except ages 20 to 29 years old where the respondents consisted only of the $20 \%$ of the entire sample to the study. All the respondents are at the age of majority. This is logical because of the nature of the research topic and the sensitivity of the needed information which involved sexual knowledge and experiences. Out of the total 100 percent $50 \%$ are at the age ranges $40-59$ years old. Almost all are at the age of maturity which can assure accuracy of the information based on this level of understanding.

Only three of the respondents are male while 117 are females. The findings only confirmed the study undertaken using the ever married women as the respondents. The choice of respondents is also based on the original participants to the regular HIV AIDS seminars sponsored by the RHU4 of San Jose City. The criteria for the purposive sampling are set and presented in the methodology part.

In terms of religious affiliation, almost all (98\%) out of 120 respondents belonged to Roman Catholic Church. This is parallel to the study conducted in sub Saharan region of Africa where religious belief and weakening of family values help enhance spread of the deadly disease. Only three 3 percent are non-members of the Roman Catholic Church. 
Table 1. Profile of the respondents.

\begin{tabular}{|c|c|c|}
\hline Age & Frequency & Percent \\
\hline 20 to 29 & 24 & 20.0 \\
\hline 30 to 39 & 30 & 25.0 \\
\hline 40 to 49 & 31 & 25.8 \\
\hline 50 to 59 & 31 & 25.8 \\
\hline 60 and above & 4 & 3.3 \\
\hline Total & 120 & 100.0 \\
\hline Gender & Frequency & Percent \\
\hline 1 & 3 & 2.5 \\
\hline 2 & 117 & 97.5 \\
\hline Total & 120 & 100.0 \\
\hline Civil Status & Frequncy & Percent \\
\hline 1 & 21 & 17.5 \\
\hline 2 & 93 & 77.5 \\
\hline 3 & 5 & 4.2 \\
\hline 4 & 1 & 0.8 \\
\hline Total & 120 & 100.0 \\
\hline Religion & Frequency & Percent \\
\hline 1 & 98 & 81.7 \\
\hline 2 & 3 & 2.5 \\
\hline 3 & 10 & 8.3 \\
\hline 5 & 9 & 7.5 \\
\hline Total & 120 & 100 \\
\hline
\end{tabular}

In terms of the fact of marriage, 77.5 percent are married while only 1 is single. It must be noted that the disease is transmitted thru sexual intercourse and use of syringes and medical instruments. Therefore, if prevention is the goal then married individuals should be the first to undergo seminars and trainings on HIV AIDS prevention.

The following tables show the respondents' knowledge, beliefs and attitudes to AIDS/HIV. The measurement was done using the following verbal description and numerical mean scores, to wit;

1.00 to 1.74 Strongly Disagree

1.75 to 2.49 Disagree

2.50 to 3.24 Agree

3.25 to 4.00 Strongly Agree.

\subsection{Understanding of HIV in Terms of}

The question items above (Table 2) consisted of basic knowledge on HIV/AIDS. 
Table 2. Measures of the respondents' knowledge.

\begin{tabular}{ccc}
\hline \multirow{2}{*}{ Knowledge } & Weighted & Verbal \\
\cline { 2 - 3 } 1) AIDS is communicable & Mean & Description \\
2) AIDS is Transmitted & 3.60 & Strongly Agree \\
3) AIDS Attacks the Immune System & 3.50 & Strongly Agree \\
4) AIDS is without care & 3.62 & Strongly Agree \\
5) Isolation of AIDS victim & 3.03 & Agree \\
6) Social support system is necessary to cope with AIDS & 3.63 & Agree \\
7) Age with High Risk of contamination & 2.42 & Disagree \\
8) AIDS can cause immediate death & 1.95 & Disagree \\
9) AIDS victim is a shame in society & 2.23 & Disagree \\
10) AIDS affects all ages & 2.35 & Disagree \\
Overall Weighted Mean & 2.89 & Agree \\
\hline
\end{tabular}

Notable is the knowledge of the respondents on HIV/AIDS as a disease transmitted through syringe and the need to provide support system to persons afflicted with the virus. Items 1, 2, 3 and 6 showed the above average knowledge on the nature of AIDS and the need to help person having AIDS, by the community especially immediate love ones and relatives. The findings are supported by the study conducted in a school of nursing in Barcelona where support system is considered as one of the important factors for a victim to cope with the challenge of being contaminated with the virus [16]. It is to be noted also that greater majority of the respondents are mothers and by their very nature supportive of whatever trials family members are facing. The finding suggests the greater role that mothers could perform to cope with the depression that AIDS could bring to individuals. The study of the ever married women of Bangladesh where the study proved that they are more vulnerable to AIDs compared to other members of the community [17]. The verbal description of strongly agree on the afore cited items manifested higher degree of understanding on the part of the respondents in so far as such ideas are concerned. Noteworthy is the verbal description on responses on item questions numbers $7,8,9$, and 10 where the respondents showed a "disagree" position on the "high risk of contamination among young adolescents", and the nature of AIDS as "causing immediate death" to its victims. Even though couched in the positive these items are commonly misinterpreted if products of AIDS myth and not based on facts. Therefore, one may deduce that the respondents' knowledge on the basic information pertaining to AIDs is quite high and is desirable as shown by the highest WM of 3.6 and the low weighted mean to myths as 1.95 .

\subsection{Beliefs}

Belief is the way a person thinks and gives meaning to a certain thing, event or a 
phenomenon. It is a function of knowledge on a thing upon which he or she entertains certain concept. Beliefs influence a person's acts and behaviors. The following scores and verbal description show the beliefs of the respondents on matters regarding AIDS.

As the table shows 5 of the items presented before the respondents showed their "disagreement."Meaning, if one considers his belief they would not agree to the scenario cited which a great part is a function of their held beliefs. Items number 3, 4, 7, 8, 9 are not part of the beliefs of the respondents if one looks into the deducible logic of their responses. Items 3 and 4 revealed the held beliefs of the respondents on the inappropriateness of the scenarios in regard to transmission of AIDS virus. The respondents firmly believed that some other means could transmit AIDs virus other than the use of "spoon" and the intermediacy of a certain breed of monkey. This clearly manifests the ability of the respondents to delineate the correct knowledge in so far as transmission of virus is concerned. The lower mean scores of 2.44 and 2.13 point to the fact that such myths are not part of the beliefs of the respondents. Meanwhile the myth that only males are risk prone to AIDS and the uselessness of education campaign are also not to be considered as part of their beliefs on AIDS by looking into their consistent disagreement to the proposition. Items number 7, 8 and 9 only show that the respondents are aware of the importance of awareness campaign to AIDs and the impropriety of believing in the myth that only males are risk prone to AIDS because of the seeming sexual practices and marital infidelity committed by males more than women. This is part of the cultural orientation and exposure of the respondents to the micro culture of chauvinism prevalent in Philippine society. However, even if the same idea is attributed to cultural orientation, the majority still hold the truth that awareness campaigns make the difference. It is shown by their being "disagreed" on the pivotal role played by educational institution and the health care institutions on the prevention of AIDS virus and spread and contamination.

Noteworthy is the "unsafe sex practice" as appoint of strong agreement on the part of respondents. In fact many studies showed that this is the number 1 cause for rapid spread of deadly virus. Implicitly, the respondents' belief and its correlation to sexual practice is a point of strong agreement. It is a belief that is more $r$ less correct and beyond question. This finding also a confirmation of the respondents' strong disagreement on the fact that only males can be a victim of AIDS virus.

All in all, they have positive attitudes towards a person with age and likewise positive (meaning) agreeable understanding) of the capacity and capability of the different sectors to prevent spread of AIDS as well as correctness of their information as part of their beliefs o HIV AIDS. The Table 3 shows the responses of participants in terms of beliefs, to wit;

\subsection{Attitudes}

Part of the general understanding of HIV AIDS the study measured the attitudes 
Table 3. Measure of the respondents' as to beliefs.

\begin{tabular}{ccc}
\hline Beliefs & Weighted \\
Mean & $\begin{array}{c}\text { Verbal } \\
\text { Description }\end{array}$ \\
1) AIDS is without cure & 2.88 & Agree \\
2) Unsafe sex practice transmits AIDs & 3.37 & Strongly Agree \\
3) Transmission may be through the use of & 2.44 & Disagree \\
spoon used by AIDS victim & 2.13 & Disagree \\
4) Only monkey can transmit AIDs virus & 2.65 & Agree \\
5) Transmission can be by the use of \\
personal things of AIDs victims & 2.99 & Agree \\
6) A victim threatens the entire society & 2.00 & Disagree \\
7) Only males may be afflicted with AIDS & 2.35 & Disagree \\
8) Health education cannot prevent spread of AIDS & 2.43 & Disagree \\
9) Awareness campaign is useless to solve the problem & & Agree \\
10) AIDS is a concern of educational system & 2.70 & Agree \\
\hline Overall Weighted Mean & 2.59 &
\end{tabular}

of the respondents. Beliefs as conceived by the study are a state of mind causing a person to do a certain activity in order to become better at something. It could be interpreted as a person's mental model of something. In general, a person's attitude may be positive or negative towards a certain thing or person. In terms of the importance of "awareness campaign", the respondents believed that it plays an important role to prevent spread of HIV virus. This belief is expressed by the weighted scores of 3.33 and 3.58 equivalent to verbal description of "strongly agree". The finding is supported by catena of studies where awareness campaign is considered as a means to prevent widespread of HIV AIDS [18].

Meanwhile items 4, 6, 7 pointed to the fact of stigmatization of a person with HIV AIDS virus. The respondents exhibited a disagree responses showing the higher level of understanding in terms of belief that stigmatization does not help in the prevention of AIDS virus. Saying in effect that stigmatization must be avoided and a support system is necessary for a person to cope with AIDS. The item-numbers 5 and 8 showed the belief that it is the school that has the duty to educate people on the HIV AIDS by integrating into the curriculum. This understanding is expressed in the agreement of the respondents on the duty to propagate ideas on HIV AIDS. Awareness campaign is an effective prevention measure which schools may undertake. Item 10 on the other hand showed the belief that all social institutions have the moral responsibility to act and educate people against HIV AIDS contamination. The respondents are also informed that insufficient understanding of the issue contributes to the unprecedented increase in the number of cases of HIV AIDS victims (Table 4).

\subsection{Relationship between Respondents Profile and Level of Understanding of HIV AIDS}

There are four variables related to understanding of HIV AIDS namely, age, 
Table 4. Measure of the respondents as to attitudes.

\begin{tabular}{|c|c|c|}
\hline Attitudes & $\begin{array}{l}\text { Weighted } \\
\text { Mean }\end{array}$ & Verbal Description \\
\hline 1) Awareness campaign can prevent spread of AIDS & 3.33 & Strongly Agree \\
\hline $\begin{array}{c}\text { 2) Use of Condom reduces chances of AIDS } \\
\text { contamination }\end{array}$ & 3.21 & Agree \\
\hline 3) It is alright to discuss AIDs with adolescents & 2.82 & Agree \\
\hline $\begin{array}{l}\text { 4) Only medical institution is duty bound to prevent } \\
\text { the spread of AIDS }\end{array}$ & 2.48 & Disagree \\
\hline 5) The school has the duty to teach children on AIDS. & 2.88 & Agree \\
\hline 6) A person with AIDS must be avoided & 2.27 & Disagree \\
\hline 7) A person with age should prevent social interaction & 2.45 & Disagree \\
\hline $\begin{array}{l}\text { 8) The number of AIDs victims increases daily because } \\
\text { of insufficient understanding on causes, effects } \\
\text { and consequences }\end{array}$ & 3.13 & Agree \\
\hline $\begin{array}{l}\text { 9) AIDS lesson must be incorporated in school } \\
\text { curriculum }\end{array}$ & 3.20 & Agree \\
\hline $\begin{array}{l}\text { 10) AIDS awareness campaign must begin with the } \\
\text { family, school, church and other social } \\
\text { institutions. }\end{array}$ & 3.58 & Strongly Agree \\
\hline Overall Weighted Mean & 2.93 & Agree \\
\hline
\end{tabular}

gender, civil status and religion. The study tried to establish the connections between the four variables and their level of understanding. Using the statistical treatment of Pearson product moment correlation, the following findings are drawn.

The understanding has no significant relationship to age, gender, civil status and religion. The weighted mean scores and Pearson product value suggested that there is a relationship among variables with the dependent variable of understanding but such is insignificant and may not affect the other variable. Statistical proof showed that they are positively related. Meaning an increase in one variable may influence other variable but such is little and insignificant at .050 value of significance. The table of correlation is presented in Table 5 , to wit.

There is therefore no significant relationship between the profile of the respondents and their understanding of HIV Aids measured in terms of knowledge, belief and attitudes.

\section{Conclusions and Recommendations}

\subsection{Summary}

The development towards decentralization resulted in the devolution of many public services. From the period 2013 to 2016, the Local Government of San Jose administered and implemented the DOH programs against spread of HIV/AIDs. The study measured the level of understanding in terms of knowledge (2.89) beliefs (2.59) and attitudes (2.93). The study therefore showed median understanding of HIV/AIDS while an insignificant relationship between age, gender, civil status and religion was arrived at. 
Table 5. Measure of the respondents as to relationship between personal profile and understanding.

\begin{tabular}{ccccc}
\hline Profile & $\begin{array}{c}\text { Understanding of } \\
\text { HIV Aids, r-value }\end{array}$ & p-value & alpha & interpretation \\
\hline Age & 0.075 & 0.416 & 0.05 & No significant relationship \\
Gender & 0.069 & 0.455 & 0.05 & No significant relationship \\
Civil Status & 0.104 & 0.257 & 0.05 & No significant relationship \\
Religion & -0.008 & 0.931 & 0.05 & No significant relationship \\
\hline
\end{tabular}

\subsection{Conclusions}

The study showed that there is a better understanding of the issue on HIV/AIDS among the residents of RHU4 which directly proved the hypothesis that awareness campaign provides better understanding of the issue. The hypothesis is also tested and proven to create a positive but insignificant relationship between the respondents profile and level of understanding. The relationship is positive but is inadequate to establish that one variable affects the other.

The study showed the impact of decentralizing HIV/AIDS Education awareness campaign among the residents of RHU4 San Jose City, Nueva Ecija. The decentralization provides better understanding of the issue and proven to create positive impact on the level of awareness of the people so as to lessen if not fully eradicate the effects of the disease in the future.

\subsection{Recommendation}

Given the findings, the following recommendations are submitted:

1) A similar evaluation may be undertaken to measure the effectiveness of HIV/AIDS campaign in increasing the level of understanding of the community on the issue;

2) A periodic evaluation may be done to ensure that the money used to prevent HIV/AIDS contamination is used for the purpose and meet its objective;

3) A multi-sectoral awareness campaign be undertaken where the LGU will serve as the nexus of the multi-sectoral agreement;

4) A separate program for information dissemination purpose be undertaken to focus only on AIDS related issue. Intensifying the chances of preventing HIV/AIDS contamination.

The LGU to continuously use all forms of media to reach the widest possible reach of information. The internet and social media are effective tools for the purpose.

\section{References}

[1] Grillo, G., Ramiro, L.S., Castillo, F.A., Tan-Torres, T., Torres, C.E., Tayag, J.G., Talampas, R.G. and Hawken, L. (2001) Community Participation in Local Health Boards in a Decentralized Setting: Cases from the Philippines. Health Policy and Planning, 16, 61-69. https://doi.org/10.1093/heapol/16.suppl_2.61

[2] Bossert, T.J. and Beauvais, J.C. (2002) Decentralization of Health Systems in Ghana, Zambia, Uganda and the Philippines: A Comparative Analysis of Decision Space. 
Health Policy and Planning, 17, 14-31. https://doi.org/10.1093/heapol/17.1.14

[3] Gabriel, A.G. and Gutierrez, M.P. (2017) Praxis in Local Legislative Governance: Measure of Organizational Effectiveness of the Component Cities in Nueva Ecija, Philippines. Asia Pacific Journal of Multidisciplinary Research, 5, No. 2. http://www.apjmr.com/wp-content/uploads/2017/04/APJMR-2017.5.2.02.pdf

[4] Legaspi, P.E. (2001) The Changing Role of Local Government under a Decentralized State: The Case of the Philippines. Public Management Review, 3, 131-139. https://doi.org/10.1080/14616670010009405

[5] Gabriel, A.G. (2017) Transparency and Accountability in Local Government: Levels of Commitment of Municipal Councillors in Bongabon in the Philippines, Asia Pacific Journal of Public Administration, 39, No. 3. http://www.tandfonline.com/doi/full/10.1080/23276665.2017.1368902

[6] Guevara, M.M. (2000) Decentralization and Economic Development: The Philippine Experience. Hitotsubashi Journal of Economics, 41, 97-109.

[7] Brillantes Jr., A.B. (1998) Decentralized Democratic Governance under the Local Government Code: A Governmental Perspective. Philipine Social Science Council Knowledge Archive, Quezon City.

[8] Tan, M.L. (1993) Socio-Economic Impact of HIV/AIDS in the Philippines. AIDS Care, 5, 283-288. https://doi.org/10.1080/09540129308258611

[9] Landman, K.Z., Ostermann, J., Crump, J.A., Mgonja, A., Mayhood, M.K., Itemba, D.K. and Shao, J.F. (2008) Gender Differences in the Risk of HIV Infection among Persons Reporting Abstinence, Monogamy, and Multiple Sexual Partners in Northern Tanzania. PloS One, 3, e3075. https://doi.org/10.1371/journal.pone.0003075

[10] Otani, J. (2004) HIV/AIDS and Older People. 15th International Conference on AIDS, Bangkok, 2004.

[11] Morroni, C., Myer, L., Mlobeli, R., Gutin, S. and Grimsrud, A. (2007) Dual Protection among South African Women and Men: Perspectives from HIV Care, Family Planning and Sexually Transmitted Infection Services. University of Cape Town, Cape Town.

[12] Ellen, J.M., Gurvey, J.E., Pasch, L., Tschann, J., Nanda, J.P. and Catania, J. (2002) A Randomized Comparison of A-CASI and Phone Interviews to Assess STD/HIV-Related Risk Behaviors in Teens. Journal of Adolescent Health, 31, 26-30. https://doi.org/10.1016/S1054-139X(01)00404-9

[13] Arriola, K.J., Spaulding, A.C., Booker, C.A., Williams, C., Avery, A., Porter, N.J., Frew, P.M., et al. (2015) Understanding the Relationship between Social Support and Physical and Mental Well-Being among Jail Detainees Living with HIV. Journal of Health Psychology, 20, 3-12. https://doi.org/10.1177/1359105313496447

[14] Catane, J. (2013) Conducting Research. Goodwill Trading Co. Inc, Manila.

[15] Holsti, O.R. (1969) Content Analysis for the Social Sciences and Humanities.

[16] Villalbi, J., Cayla, J., Iglesias, B., Ferrer, A. and Casanas, P. (1994) The Evolution of Tuberculosis Infection among Schoolchildren in Barcelona and the HIV Epidemic. Tubercle and Lung Disease, 75, 105-109. https://doi.org/10.1016/0962-8479(94)90038-8

[17] Decker, M.R., Frattaroli, S., McCaw, B., Coker, A.L., Miller, E., Sharps, P., Strobino, D.M., et al. (2012) Transforming the Healthcare Response to Intimate Partner Violence and Taking Best Practices to Scale.

[18] Friedman, S. and Mottiar, S. (2005) A Rewarding Engagement? The Treatment Action Campaign and the Politics of HIV/AIDS. Politics \& Society, 33, 511-565. https://doi.org/10.1177/0032329205280928 